\title{
INFLUENCE OF THE SHAPE OF THE TEST SPECIMEN PRODUCED BY 3D PRINTING ON THE STRESS DISTRIBUTION IN THE MATRIX AND IN LONG REINFORCING FIBERS
}

\author{
HANDRIK Marián¹, VAŠKO Milan¹, MAJKO Jaroslav', SÁGA Milan", \\ DORČIAK Filip ${ }^{1}$ \\ ${ }^{1}$ University of Žilina, Faculty of Mechanical Engineering, Department of Applied Mechanics, \\ Univerzitná 8215/1,01026 Žilina, SlovakRepublic, e-mail: marian.handrik@fstroj.uniza.sk, \\ milan.vasko@fstroj.uniza.sk, jaroslav.majko@fstroj.uniza.sk,milan.saga@fstroj.uniza.sk, \\ filip.dorciak@fstroj.uniza.sk
}

\begin{abstract}
The stress distribution in specimens designed for the tensile testing is evaluated in the article. The reinforcement consists of long fibers that copy the outer contour of the specimen. The fibers are inserted within the curvature at the edge of the specimen with the neck. The stress distribution in fibers and matrix of dogbone specimen and specimen of rectangular shape is analyzed and compared. The analysis of stress state is analyzed in FEM software ADINA. Long fibers deposited in specimen were modeled using rebar elements.
\end{abstract}

KEYWORDS: carbon fiber, reinforced composite, tensile test, 3D printing, ADINA, FE analysis, MATLAB

\section{Introduction}

3D printing becomes an emerging production technology, which is gradually gaining the market place. We consider it as an additive manufacturing technology that, which in contrast to conventional subtractive technologies, is based on the addition of the material layer-bylayer according to data from the digital model of object $[1,2]$. The technology has been developing for 35 years. It currently includes several methods that differ in many parameters, for instance in used materials, in accuracy, speed of production, etc. [3]. The most widely used 3D printing method is Fused Filament Fabrication - FFF [4]. The principle of the method is based on feeding the thermoplastic filament into a nozzle in which the filament is heated. The extrusion head with the nozzle follows defined trajectory and melted material falling at the specified locations. The method was patented by Stratasys in 1989 [5]. In addition, the method allows to printing fiber reinforced thermoplastic composites which are reinforced with short or continuous fibers [6]. Continuous fiber reinforced thermoplastic (CFRTP) composites achieve better mechanical properties than their counterpart but recent research continues to improve the properties [7, 8]. CFRTP composites printing is available using augmented FFF method, when the printer is equipped with two nozzles; the second nozzle is used to lay fiber into thermoplastic part [9]. The mechanical properties of composites produced by conventional methods are better compared to 3D printed reinforced thermoplastic composites $[10,11]$; therefore primary objective is to obtain comparable results. Two main concepts, how to predict the mechanical properties of the composite structures are FEM calculations and tests performing. In FEM program ADINA, continuous fibers are modeled using rebar elements. The program automatically finds intersections of each rebar line with 3D solid element surfaces and generates nodes at the intersections. These generated nodes and three closest corner nodes of 3D solid element faces are connected using constraint equations [12]. This concept allows modeling of real continuous fiber in a matrix using real mechanical properties of the matrix and the fiber. 
The tensile tests for 3D printed reinforced thermoplastic composites are not defined yet. Hence specimen shape and testing parameters according to standards for plastics (ASTM D638-14) [13] or composites manufactured by conventional technologies (ASTM D3039) [14] are applied. The tensile tests demonstrated that dog bone specimen is inappropriate for this type of test due to occurrence of stress concentrations close to specimen attachment, in its rounding, or near the end of fibers $[15,16]$. For this reason, it is necessary to design the suitable shape of printed CFRTP specimen for tensile testing. In assessing process of the specimen shape suitability, the mechanical properties of reinforcing continuous fiber should be taken into account.

\section{Analysis of stress distribution in specimen}

Fiber deposition and its location were determined from software Eiger. Program, which generates models for FEM software ADINA was created using MATLAB $[12,17]$. The degrees of freedom were removed at one end of the specimen and displacements were prescribed on other side (Fig. 1).

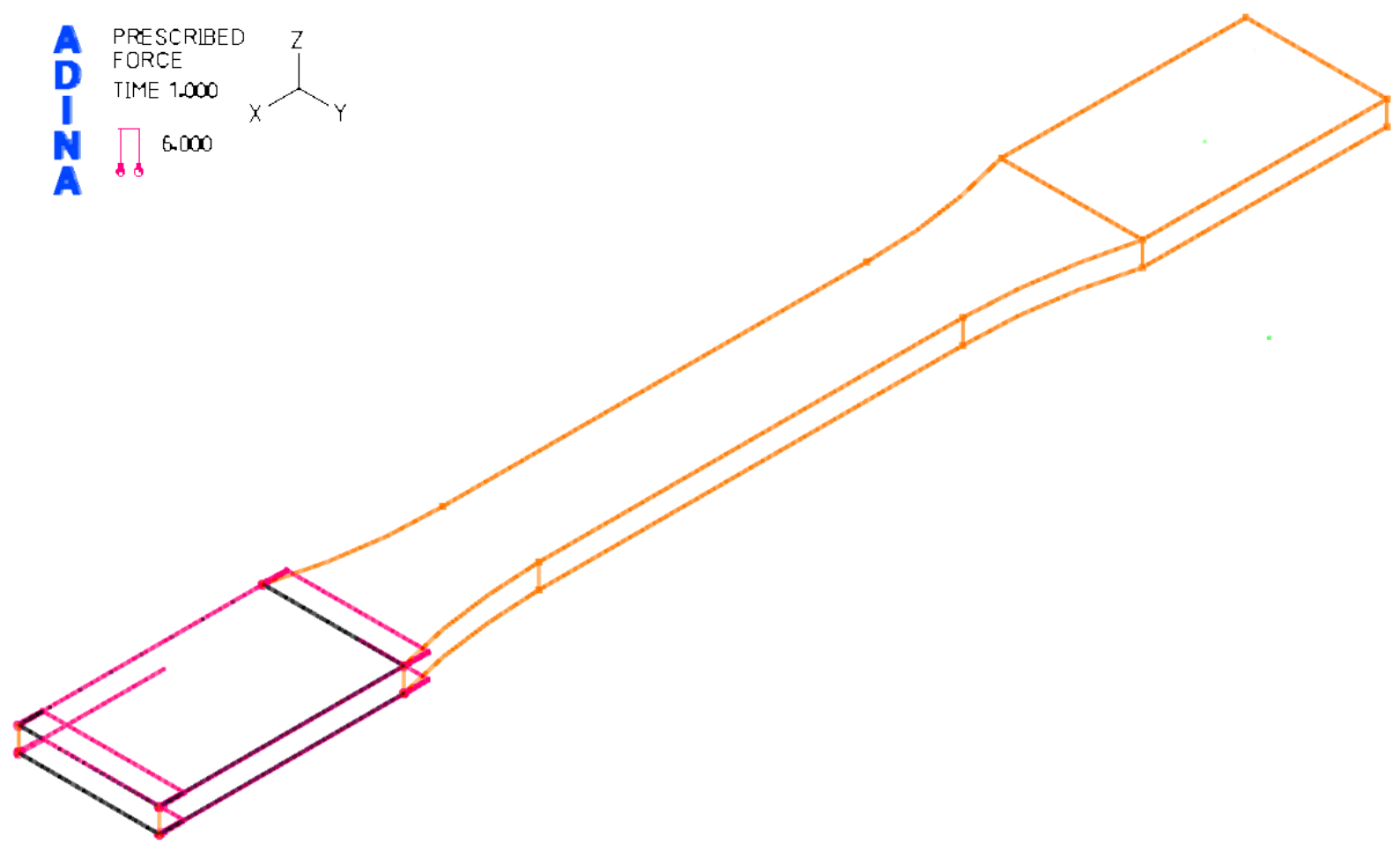

Fig. 1 Boundary conditions

The multilinear material model was used to create the specimen matrix (ONYX, Fig. 2, left) and the carbon fiber (Fig. 2, right) model. The material model of matrix and fibers was determined from experimental measurements of mechanical properties of the materials [18]. The finite element mesh was generated using $0.4 \mathrm{~mm}$ linear tetrahedron elements. These mesh elements sizing was used because provides comparable results to $0.2 \mathrm{~mm}$ elements but the usage of $0.2 \mathrm{~mm}$ elements requires more computational time. In computational process was observed the influence of elements size to resultant stress values. The sizes of assessed elements were $0.4,0.2$ and $0.1 \mathrm{~mm}$. The assessment was performed on the structure without reinforcement fibers. The stress variation affected by element sizing does not exceed $5 \%$.

In the next step, the influence of convergence criterion to solution accuracy in the reinforced model was performed. The convergence criterion of deformations was applied and 
the presented results are for value 1e-9. The selection of 1e-10 criterion leads to loss of convergence.
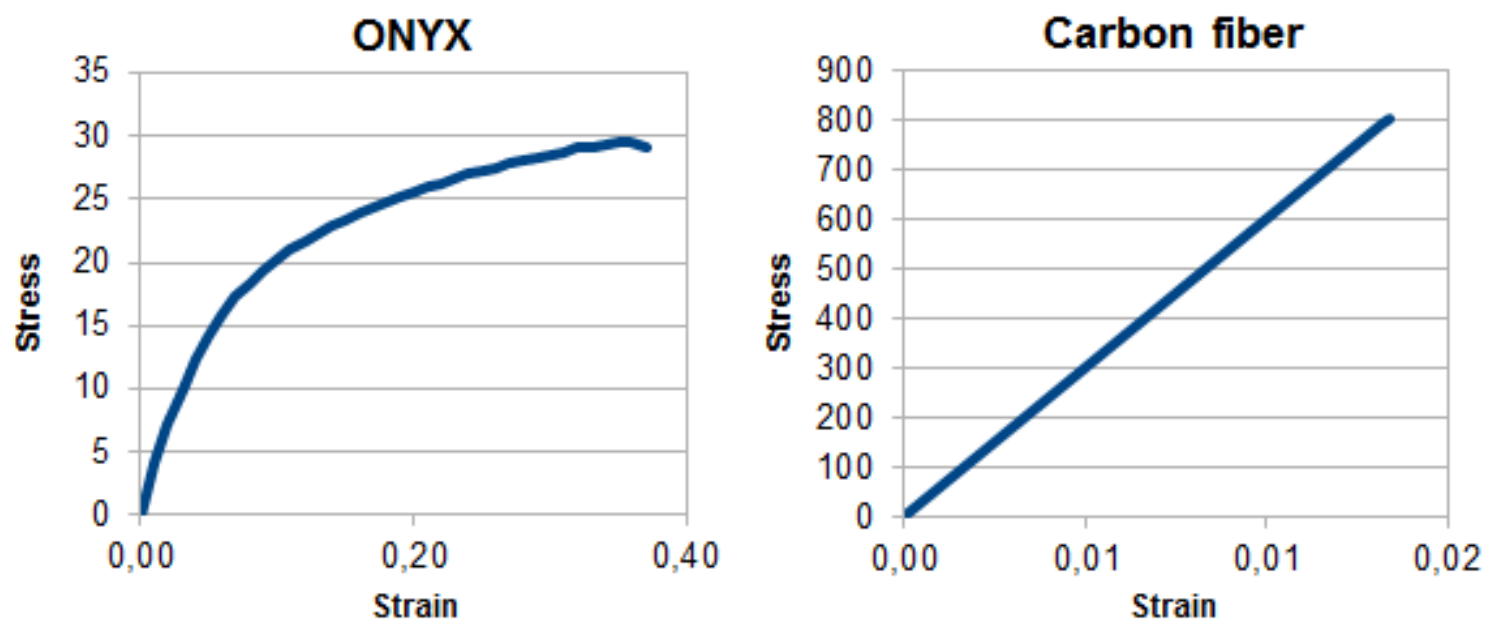

Fig. 2 Multilinear material model for the matrix (left) and for the carbon fiber (right)

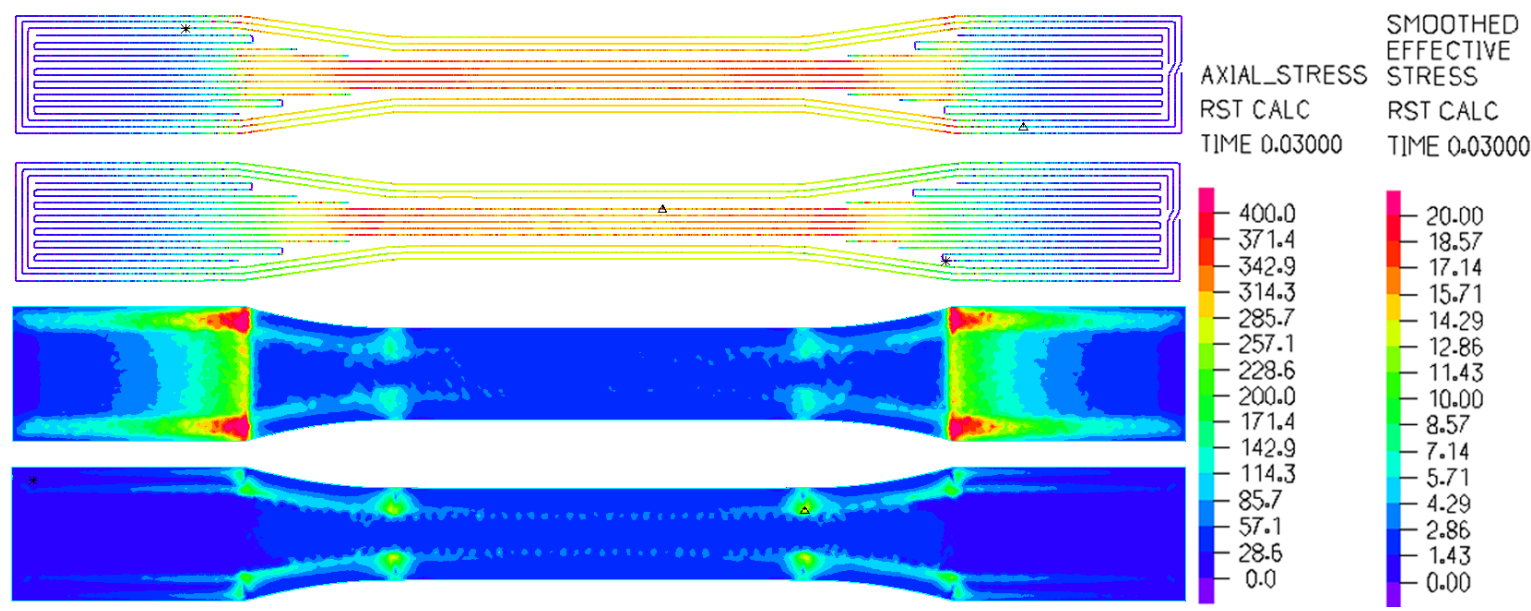

Fig. 3 Dog bone specimen reinforced with three concentric rings and isotropic fiber fill [13]

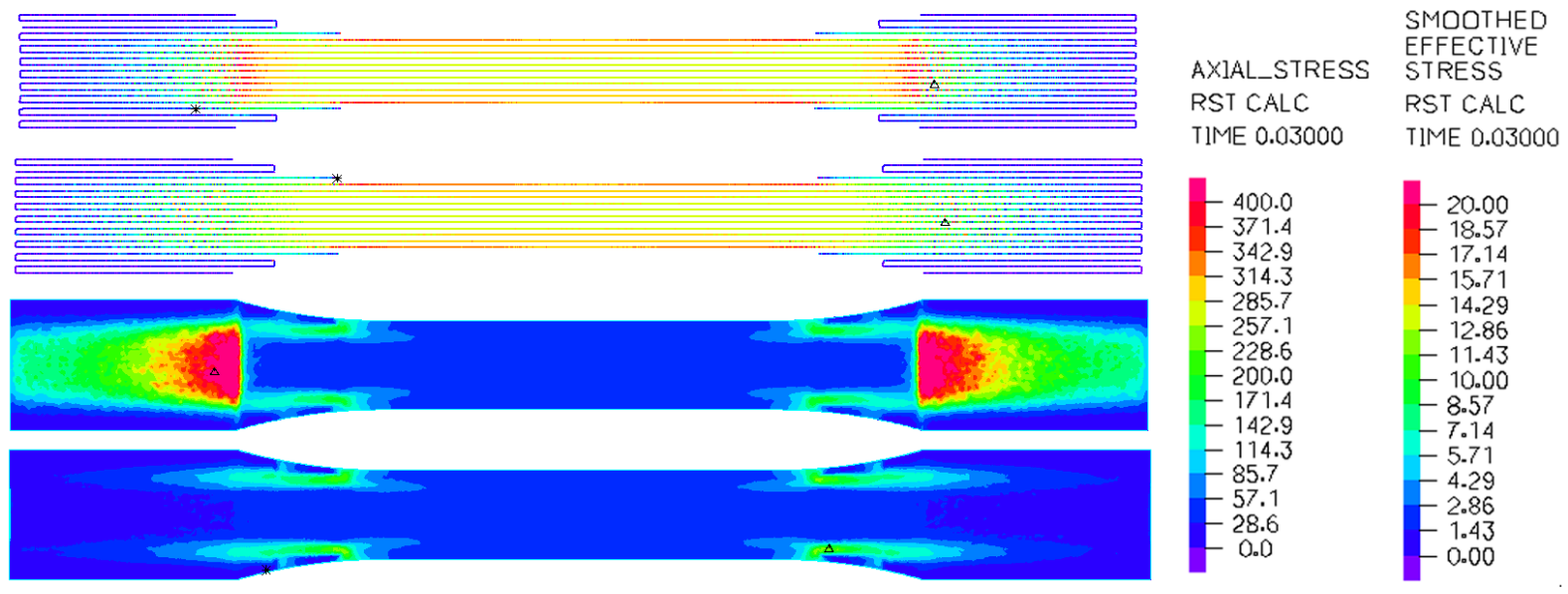

Fig. 4 Dog bone specimen reinforced with unidirectional fiber fill [13] 

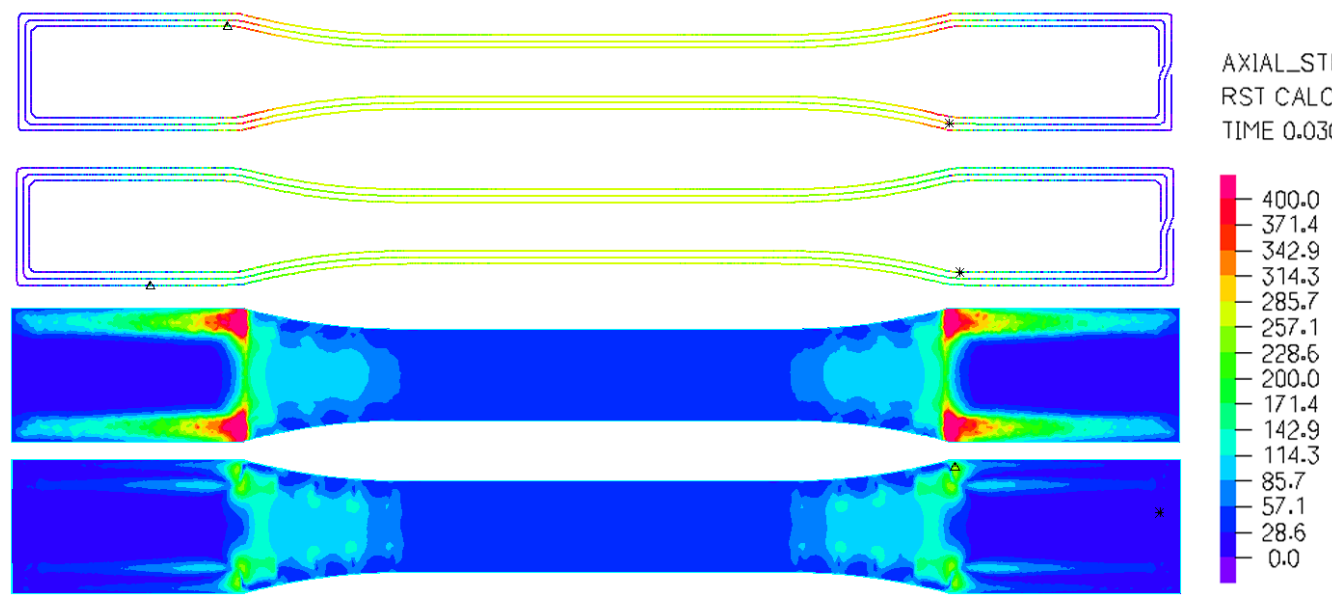

Fig. 5 Dog bone specimen reinforced with three concentric rings of fiber fill [13]
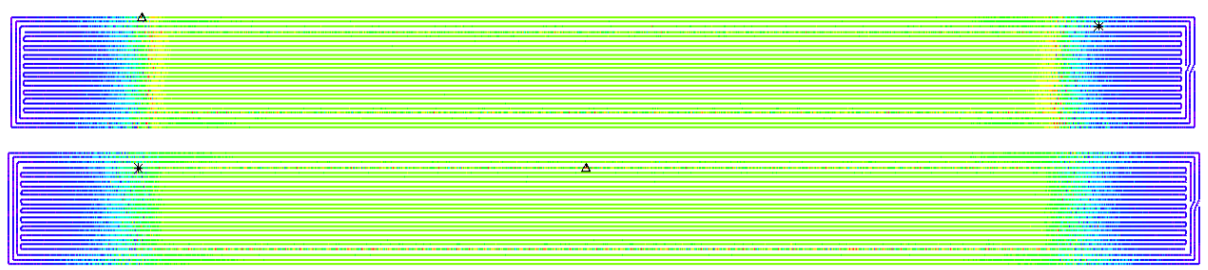

AXIAL_STRESS RST CALC TIME 0.03000

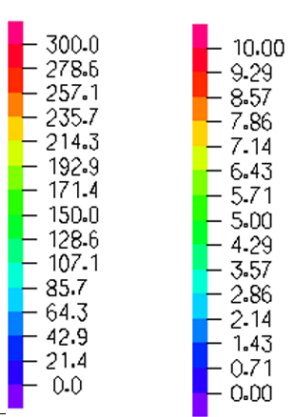

Fig. 6 Rectangular specimen reinforced with three concentric rings and isotropic fiber fill [14]

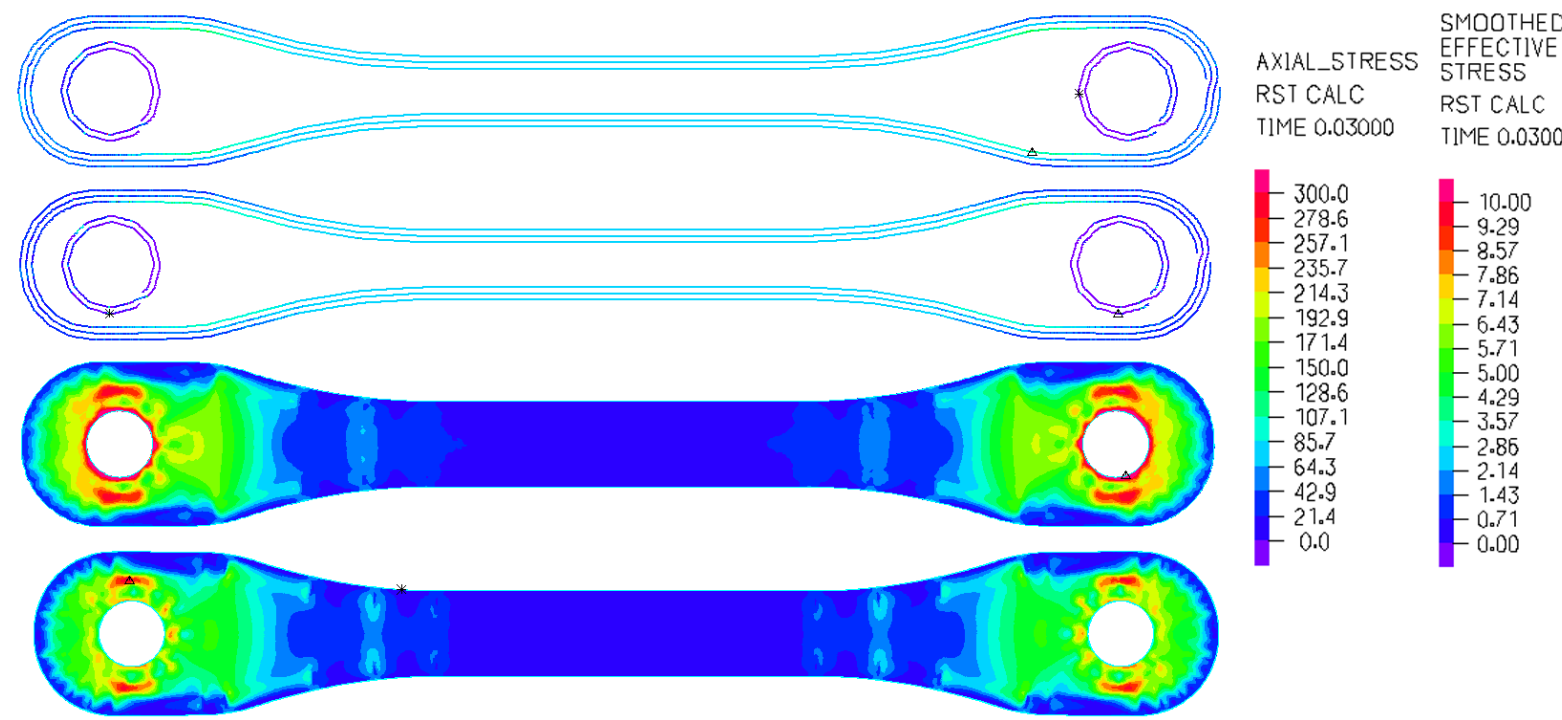

Fig. 7 Adjusted dog bone specimen reinforced with three concentric rings of fiber fill [19]

The stress distribution in specimens is shown in Fig. 3 to Fig. 7 in defined order:

- stress distribution in the fiber, which is closest to outer surface of the specimen, 
- stress distribution in the fiber, which is deposited in the middle layer of the specimen,

- stress distribution in the matrix on the specimen outer surface,

- stress distribution in the matrix in the middle of the specimen.

The stress distribution inhomogeneity on the specimen outer surface and in the middle of the specimen can be observed in four assessed specimen shapes (from Fig. 3 to Fig. 6). This uneven stress distribution is due to the boundary condition - attachment of the specimen to the jaws. Increased values of stress occur in the specimen matrix surface and in outer reinforced layers. Therefore, for these specimens the attachments cause beginning of the specimen breakage. The last analyzed specimen shape (Fig. 7) has equal stress distribution in the outer fibers and in the fibers localized in the middle of the specimen. This specimen has significantly higher stress values around the attachment hole. We can assume, that start of the breakage occurs at this location. Significantly different dimensions of specimens results to differences of stress values in matrix and fibers.

\section{Proposal of new specimen shape}

In general, each analyzed specimen shape in the article is inappropriate for the experimental measurements of mechanical properties of continuous fiber reinforced composites produced by $3 \mathrm{D}$ printing. The suitable specimen shape for tensile testing should satisfy the following conditions:

- the specimen waist should be significantly narrower than the end of the specimen,

- the radiuses on the specimens should be significantly larger, it is necessary to minimize changes in the direction of the fiber in the arc,

- reinforcing fibers should be deposited in rings because the fiber ends result to significant stress concentration.

Proposed specimen shape is in Fig. 8. The specimen was divided into eleven layers and reinforced with carbon fiber in three layers. Fiber fill type was concentric with four fiber rings. The reinforcing fiber has tensile strength $700 \mathrm{MPa}$ at strain 0,0134 and fiber diameter $0,37 \mathrm{~mm}$. Total number of fibers in the narrowest part of specimen was 24 . Therefore the force required to rupture of the fibers is $1800 \mathrm{~N}$. The matrix in the narrowest part of specimen has cross section area $13,75 \mathrm{~mm}^{2}$. Onyx has tensile strength 5,2 $\mathrm{MPa}$ at strain 0,0134 and force required to rupture is $143 \mathrm{~N}$.

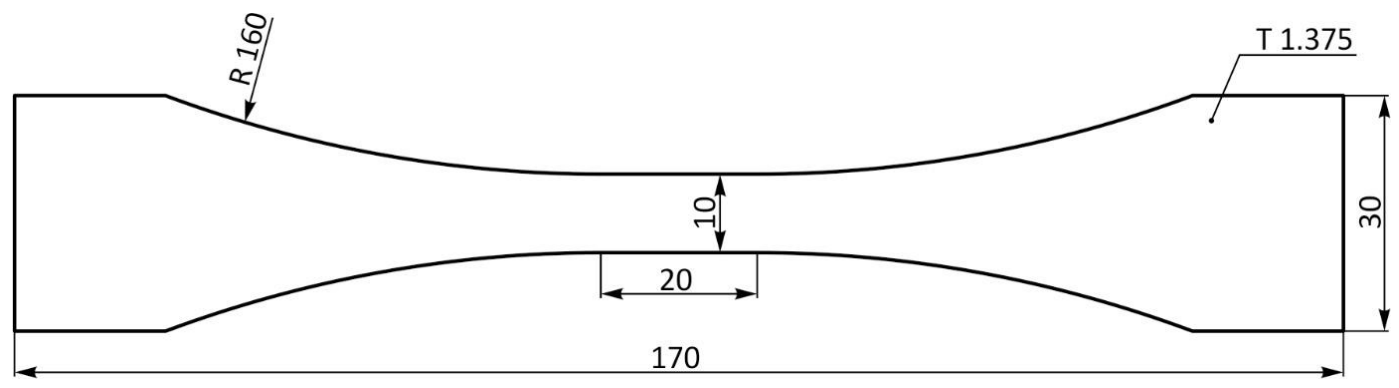

Fig. 8 Proposed specimen shape for tensile testing

Therefore reinforcing fibers have significant influence on specimen strength. State of stress in the specimen is showed in Fig. 9. There are minimal differences in stress distributions 
between outer and middle reinforced layers. The maximum stress in fibers occurs in the narrow part of specimen. Curved fiber deposition has minimal effect on stress state in specimen.

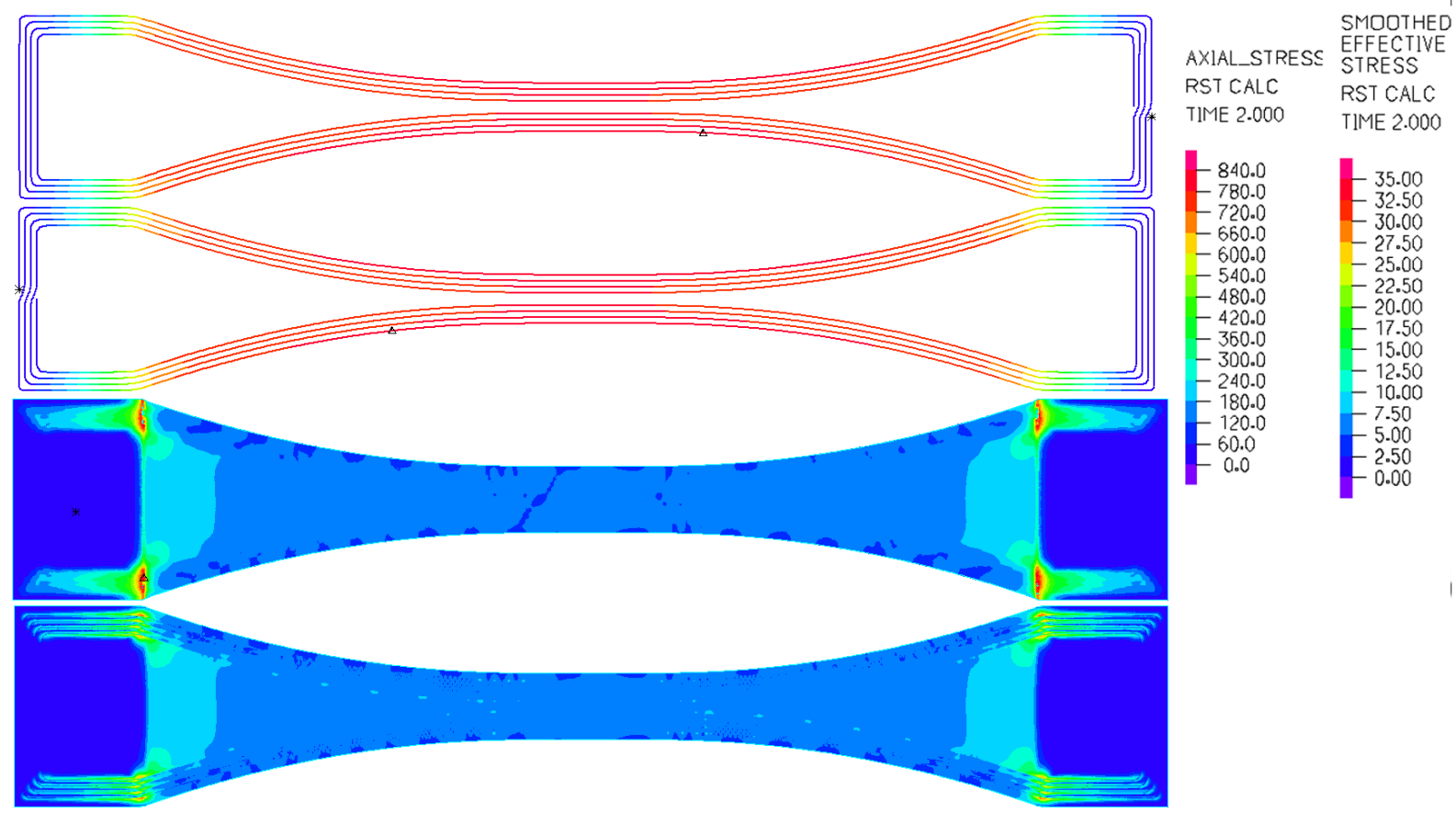

Fig. 9 Von Mises stress distribution in proposed specimen

\section{CONCLUSION}

Based on the analysis of the stress state in assessed three tensile test specimens for longreinforcing fibers, we can make the following statement. Specimens shapes defined in standards ASTM D3039, ASTM D638-14 and article [17] are inappropriate for tensile testing of 3D printed CFRTP composites. Large differences of stress state in outer and middle reinforced layers may result to rupture of fibers from outer layers to the middle of the specimen. Wide variations of specimen shapes cause the occurrence of stress concentrations in these locations, that may influence crack formation. Specimen shape unsuitability affects material inhomogeneity on a macroscopic scale. The proposed new shape of the specimen eliminates these described deficiencies. The proposed number of reinforcing layers, the shape of fibers and deposition of fibers in the matrix has a significant influence on the resultant strength of the specimen. These parameters are the primary factors determining the strength of the composite structure. Extension of specimen ends eliminates the generation of stress concentrators caused by the attachment of specimen to test machine.

\section{ACKNOWLEDGEMENTS}

This work was supported by KEGA project No. 037ŽU-4/2018.

\section{REFERENCES}

[1] ASTM F2792-12a Standard Terminology for Additive Manufacturing Technologies, (Withdrawn 2015), ASTM International, West Conshohocken, PA, 2012. Available at: www.astm.org

[2] Dimić, A., Mišković, Ž., Mitrović, R., Ristivojvić, M., et al. „The Influence of Material on the Operational Characteristics of Spur Gears Manufactured by the 3D Printing 
Technology“, Strojnícky časopis - Journal of Mechanical Engineering 68 (3), pp 261 270, 2018. DOI: $10.2478 /$ scjme-2018-0039

[3] Ngo, T. D., Kashani, A., Imbalzano, G., Nguyen, K. T. Q., Hui, D. "Additive manufacturing (3D printing): A review of materials, methods, applications and challenges", Composites Part B 143, pp. 172 - 196, 2018. DOI: https://doi.org/10.1016/j.compositesb.2018.02.012

[4] Parandoush, P., Lin, D. "A review on additive manufacturing of polymer fiber composites", Composite Structures 182, pp. $36-53$, 2017. DOI: https://doi.org/10.1016/j.compstruct.2017.08.088

[5] Crump, S. S., Stratasys, Inc., "Apparatus and method for creating three-dimensional objects", United States, US5121329A, 1989.

[6] van de Werken, N., Hourley, J., Khanbolouki, P. "Design considerations and modeling of fiber reinforced 3D printed parts", Composites Part B 160, pp. 684 - 692, 2019. DOI: https://doi.org/10.1016/j.compositesb.2018.12.094 [DOI]

[7] Ranakoti, L., Pokhriyal, M., Kumar, A. „Natural Fibers And Biopolymers Characterization: A Future Potential Composite Material“, Strojnícky časopis - Journal of Mechanical Engineering 68 (1), pp 33 - 50, 2018. DOI: 10.2478/scjme-2018-0004

[8] Goh, G. D., Dikshit, V., Nagalingam, A. P., Goh, G. L., Agarwala, S., Sing, S. L., Wei, J., Yeong, W. Y. "Characterization of mechanical properties and fracture mode of additively manufactured carbon fiber and glass fiber reinforced thermoplastics", Material Design 137, pp. $79 \quad-89$, 2018. DOI: https://doi.org/ 10.1016/j.matdes.2017.10.021

[9] Crease, A. "3D printer types \& technologies", [online]. Available at: https://markforged.com/learn/3d-printer-types-technologies [Accessed: 1403 2019]

[10] Tekinalp, H. L., Kunc, V., Velez-Garcia, G. M., Duty, Ch. E., et al. "Highly oriented carbon fiber-polymer composites via additive manufacturing", Composite Sciences and Technology 105, pp. $144-150$, 2014. DOI: https://doi.org/10.1016/ j.compscitech.2014.10.009

[11] Wang, Y. "Mechanical Properties of Stitched Multiaxial Fabric Reinforced Composites From Manual Layup Process”, Applied Composite Materials 9, pp 81 - 97, 2002.

[12] ADINA, Theory and Modelling guide, Vol. I, Adina structure. [help manual] 2017.

[13] ASTM D638-14, Standard Test Method for Tensile Properties of Plastics, ASTM International, West Conshohocken, PA, 2014. Available at: www.astm.org

[14] ASTM D3039/D3039M-17, Standard Test Method for Tensile Properties of Polymer Matrix Composite Materials, ASTM International, West Conshohocken, PA, 2017. Available at: www.astm.org

[15] Melenka, G. W., Cheung, B. K. O., Schofield, J. S., Dawson, M. R., Carey, J. P. "Evaluation and prediction of the tensile properties of continuous fiber-reinforced 3D printed structures", Composite Structures 153, pp. 866 - 875, 2016. DOI: https://doi.org/10.1016/j.compstruct.2016.07.018

[16] Kvalsvig, A., Yuan, X., Potgieter, J., Cao, P. “3D printing of fibre reinforced honeycomb structured composite materials," M2VIP 2016 - Proc. 23rd Int. Conf. Mechatronics Mach. Vis. Pract., 2017. 
[17] Moravec, J., Kopas, P., Jakubovičová, L., Leitner, B. "Experimental casting of forging ingots from model material" MATEC Web of Conferences 157 (05017), pp. 1 - 8, 2018. DOI: https://doi.org/10.1051/matecconf/201815705017

[18] Vaško, A., Belan, J., Tillová, E. "Study of the fatigue behaviour of synthetic nodular cast irons at low and high frequency cyclic loading", MATEC Web of Conferences 157 (07014), pp. 1 - 9, 2018. DOI: https://doi.org/10.1051/matecconf/201815707014

[19] dos Santos, J. A. P., "Additive manufacturing of thermoplastic matrix composites", Masters Dissertations, Universidade do Porto, 2017. 